\title{
Teks Mitos Tirta Selaka di Pura Kereban Langit Desa Sading Kecamatan Mengwi: Analisis Struktur dan Fungsi
}

\author{
Ni Kadek Surya Dewi Indah Sari ${ }^{* 1}$, Tjok Istri Agung Mulyawati ${ }^{2}$, I Ketut Ngurah \\ Sulibra $^{3}$ \\ ${ }^{[123]}$ Prodi Sastra Bali, Fakultas Ilmu Budaya, Universitas Udayana \\ ${ }^{1}$ [suryadewiindah435@gmail.com] 2[tiamulya59@gmail.com] \\ ${ }^{3}$ [ngurahsulibra@gmail.com] \\ *Coresponding Author
}

\begin{abstract}
This analysis aims to reveal the structure and express the function contained in the text of the myth of Tirta Selaka in the Kereban Langit Temple. In this research used structural theory and functional theory. Methods and techniques used in this study are divided into three stages: (1) Methods and techniques of data provisioning using observation methods and interview techniques assisted by purposive sampling techniques, recording techniques, recording techniques and translation techniques. (2) Methods and techniques of data analysis using qualitative methods and descriptive analytic techniques. (3) Methods and techniques of presentation of data results using informal methods supported by deductive and inductive techniques. The results obtained from this study, namely narrative structure include: nine incidents, using a straight groove and the groove is divided into five stages, situations (penyituasian), generating circumstances (incidence of conflict), Rising Action (increased conflict), Climax (climax), denoument (problem solving). The characters are divided into two, namely the main character and the secondary figure. The theme that built the text of the myth of Tirta Selaka is a magical theme. Background is divided into three, ie background place, background, and social background. In addition, this research reveals the functions contained in the text of the myth of Tirta Selaka in the Kereban Langit Temple, including: religious functions, educational functions, magical functions, and as a means of legalization of institutions and cultural institutions.
\end{abstract}

Keywords: text, myth, structure, function

\begin{abstract}
Abstrak
Penelitian terhadap teks mitos Tirta Selaka di Pura Kereban Langit ini membahas tentang analisis struktur dan fungsi. Analisis ini mempunyai tujuan untuk mengungkapkan struktur dan mengungkapkan fungsi yang terkandung dalam teks mitos Tirta Selaka di Pura Kereban Langit. Dalam penelitian ini digunakana teori struktural dan teori fungsional. Metode dan teknik yang digunakan dalam penelitian ini dibagi menjadi tiga tahapan yakni: (1) Metode dan teknik penyediaan data menggunakan metode observasi dan teknik wawancara dibantu dengan teknik purposive sampling, teknik rekaman, teknik pencatatan dan teknik terjemahan. (2) Metode dan teknik analisis data menggunakan metode kualitatif dan teknik deskriptif analitik. (3) Metode dan teknik penyajian hasil data menggunakan metode informal didukung dengan teknik deduktif dan induktif. Hasil yang diperoleh dari penelitian ini, yakni struktur naratif meliputi: sembilan insiden, menggunakan alur lurus dan alur dibagi menjadi lima tahap, situation (penyituasian), generating circumstances (timbulnya konflik), Rising Action
\end{abstract}


(peningkatan konflik), Climax (klimaks), denoument (penyelesaian masalah). Tokoh dibagi menjadi dua, yakni tokoh utama dan tokoh sekunder. Tema yang membangun teks mitos Tirta Selaka yaitu tema magis. Latar dibagi menjadi tiga, yakni latar tempat, latar waku, dan latar sosial. Selain itu penelitian ini mengungkapkan fungsi yang terkandung pada teks mitos Tirta Selaka di Pura Kereban Langit, meliputi: fungsi religius, fungsi pendidikan, fungsi magis, dan sebagai alat pengesahan pranata dan lembaga kebudayaan.

Kata kunci: teks, mitos, struktur, dan fungsi.

\section{Pendahuluan}

Karya sastra lisan adalah karya sastra yang bentuknya murni lisan, sastra lisan dikatakan sebagai sastra yang disampaikan dari mulut ke mulut. . Sastra lisan merupakan karya sastra dalam bentuk ujaran (lisan). Bentuk dari sastra lisan itu sendiri dapat berupa prosa (seperti mite, dongeng, dan legenda). Sastra lisan merupakan karya sastra dalam bentuk ujaran (lisan). Bentuk dari sastra lisan itu sendiri dapat berupa prosa (seperti mite, dongeng, dan legenda). Fungsi dari sastra lisan sendiri tidak hanya sekedar untuk kebutuhan seni melainkan terdapat pula unsur pendidikan yang hendak disampaikan didalamnya, seperti nilai moral dan nilai agama dalam masyarakat (Hutomo, 1991: 21).

Mitos atau mite adalah cerita prosa rakyat yang tokohnya para dewa atau makhluk setengah dewa yang terjadi di dunia lain pada masa lampau dan dianggap benar-benar terjadi oleh yang empunya cerita atau penganutnya. Keunikan dan kekhasan yang dimiliki oleh teks mitos ini membuat penulis tertarik untuk mengkaji lebih dalam mengenai teks mitos Tirta Selaka di Pura Kereban Langit Desa Sading. Para pasangan suami istri yang belum memiliki keturunan, datang ke sana memohon agar dapat diberikan penerus keturunan/generasi dan pemohon yang lainnya datang untuk memohon kesembuhan. Masyarakat setempat khususnya masyarakat di Desa Sading mempercayai mitos Tirta Selaka di Pura Kereban Langit dari keberadaan Tirta Selaka yang terdapat di sebelah kanan padma, terdapat pancoran Tirta Selaka dengan berhiaskan relief Bima di dalam Goa Pura Kereban Langit. Dewa yang dipuja untuk Tirta Selaka yaitu Ida Bhatara Siwa Lingsir.

Teks mitos Tirta Selaka ini merupakan salah satu hasil karya sastra lisan yang keberadaanya pantas untuk dijaga dan dilestarikan. Maka dari itu sudah sewajarnya bagi perangkat desa atau masyarakat yang mengetahui mitos ini sangat penting untuk menyampaikan kepada penerus generasi tentang keberadaan bahwa awal dari keberadaan mitos ini, bukan hanya menyampaikan hal yang harus dilakukan selanjutnya tanpa mengetahui awalnya. Masyarakat yang masih mempercayai mitos Tirta Selaka sampai sekarang, diharapkan masih tetap mempertahankan keaslian cerita secara turun temurun dan menjadikan Tirta Selaka sebagai kekayaan budaya lokal sehingga bisa diketahui oleh generasi berikutnya.

\section{Pokok Permasalahan}

1. Bagaimana struktur yang membangun teks mitos Tirta Selaka di Pura Kereban Langit, Desa Sading, Kecamatan Mengwi?

2. Fungsi apa yang membangun teks mitos Tirta Selaka di Pura Kereban Langit Desa Sading, Kecamatan Mengwi?

\section{Tujuan Penelitian}

\section{Tujuan Umum}

Secara umum penelitian ini mempunyai tujuan yaitu mengembangkan salah satu aspek kebudayaan Indonesia serta bertujuan 
untuk memperoleh pengetahuan dan pemahaman yang lebih mendalam mengenai keberadaan teks Mitos Tirta Selaka di Pura Kereban Langit Desa Sading, Kecamatan Mengwi.

\section{Tujuan Khusus}

1. Untuk mendeskripsikan struktur teks mitos Tirta Selaka di Pura Kereban Langit Desa Sading, Kecamatan Mengwi.

2. Untuk mendeskripsikan fungsi teks mitos Tirta Selaka di Pura Kereban Langit Desa Sading, Kecamatan Mengwi.

\section{Metode Penelitian}

\section{Metode dan Teknik Penyediaan Data}

Metode yang digunakan dalam proses penyediaan data sangat berkaitan dengan penelitian ini, yang pertama adalah menggunakan metode observasi Metode observasi adalah metode pengumpulan data melalui pengamatan langsung atau peninjauan secara cermat dan langsung di lapangan atau lokasi penelitian. Teknik wawancara juga dilakukan wawancara dengan narasumber. Teknik wawancara ini merupakan teknik utama yang dipakai dalam penelitian yaitu menanyakan kepada narasumber yang mengetahui cerita (mitos) tersebut dibantu dengan teknik purposive sampling, yaitu dengan memilih informan kunci yaitu pemangku Pura Kereban Langit, Bendesa Adat, serta masyarakat umum. Selain itu juga menggunakan teknik merekaman berfungsi untuk merekam apa yang disampaikan oleh narasumber dan dibantu dengan teknik catat dan teknik terjemahan. Teknik terjemahan dilakukan secara harfiah dan idiomatis.

\section{Metode dan Teknik Analisis Data}

Dalam tahapan analisis data, peneliti menggunakan metode kualitatif dikarenakan metode ini secara keseluruhan memanfaatkan cara-cara penafsiran dengan menyajikan dalam bentuk deskripsi. Metode kualitatif memberikan perhatian terhadap data alamiah, data dalam hubungannya dengan konteks keberadaannya Sedangkan teknik yang digunakan adalah teknik deskriptif analitik yaitu teknik yang dilakukan dengan cara mendeskripsikan fakta-fakta yang kemudian disusul dengan analisis.

\section{Metode dan Teknik Penyajian Hasil Analisis Data \\ Dalam tahapan ini, hasil analisis} disajikan dengan metode informal. Metode informal digunakan untuk menyajikan hasil analisis data dalam bentuk kata-kata biasa serta mudah dipahami dan bukan dalam bentuk angka-angka. Tahap ini didukung dengan menggunakan teknik deduktif dan teknik induktif.

\section{Pembahasan}

Struktur Teks Mitos Tirta Selaka di Pura Kereban Langit Desa Sading Kecamatan Mengwi

- Plot/alur Teks Mitos Tirta Selaka di Desa Sading Kecamatan Mengwi

Plot merupakan unsur jalan cerita atau tepatnya peristiwa demi peristiwa yang susul-menyusul, namun hanya sekedar jalan cerita. Menurut Nurgiyantoro (2002: 113148) mengatakan bahwa alur adalah cerita yang berisi kejadian yang dihubungkan secara sebab akibat, yaitu peristiwa yang satu disebabkan atau menyebabkan peristiwa lain. Alur yang terdapat pada teks mitos Tirta Selaka dimulai dari tahap awal yaitu Tahap situation atau tahap penyituasian, pengenalan Mangku Tunden yang berasal dari Desa Bantiran. Perhatikan kutipan berikut:

"Dugas ipidan, ada anak ne maadan Mangku Tunden uli Desa Bantiran. Kaadanin Mangku Tunden krana kawitan ipune ipidan satata ngamong dadi pamangku, sakewala ipun newek konden dadi mangku sangkaning ento ipun kasengguh Mangku Tunden”. 
Terjemahan:

"Pada jaman dahulu ada seseorang bernama "Mangku Tunden" yang berasal dari Desa Bantiran. Diberi nama "Mangku Tunden" karena beliau adalah orang yang berasal dari keturunan pemangku, tetapi beliau sendiri belum menjabat sebagai pemangku yang sah maka dari itu beliau dijuluki "Mangku Tunden". Sesuai dengan namanya yaitu Tunden yaitu artinya "suruh".

Pada tahap generating circumstances atau tahap pemunculan konflik yaitu menghilangnya keris yang dibawa oleh Mangku Tunden dalam perjalanan ke Kerajaan Mengwi. Dengan rasa penuh kejujuran akhirnya Mangku Tunden menyerahkan sarung kerisnya saja. Seperti kutipan berikut.

"I Mangku Tunden katunden olih Sang Prabu ngaba keris ka Puri Mengwi, ring salantang margin ipune nuju Mengwi ritatkala maekin genah Pura Manik Galuh ring desa Perang, kerise ento malesat ilang uli saungnyane, dija kaden ilangne nyen mirib ne nyemak kerise ento tuara ja tawang. Mangku Tunden makesiab sangkaning tuara ja tawang kerise ento ilang tuah nyisaang saungne dogen.

Terjemahan :

"I Mangku Tunden disuruh oleh Sang Prabu membawa keris ke Puri Mengwi, di dalam perjalanan menuju Mengwi kira-kira mendekati Pura Manik Galuh dekat daerah Perang. Keris tersebut tiba-tiba melecat atau hilang dari sarungnya, entah kemana perginya dan siapa yang mengambilnya. Mangku Tunden sendiri terkejut dan tidak tahu kenapa kerisnya bisa tiba-tiba menghilang yang tersisa hanya sarungnya saja.

Pada tahap Rising action (peningkatan konflik) diceritakan Mangku Tunden tetap menghaturkan sarungnya saja walaupun kerisnya sudah tidak ada. Jika sarung keris ini tidak dihaturkan, Mangku Tunden akan dianggap berbohong oleh Sang Raja.. Seperti dalam kutipan berikut.

"Sangkaning baktin ipune ring ida Sang Prabu, yadiastun neтu kapiambeng ipun ngelanturang memargi ngaturang saungne dogen yadiastun kerisne suba ilang. Yening I Mangku Tunden tusing ada tangkil ring Sang Prabu ngaturang kerise ento, I Mangku Tunden karaosang pangkah bani mogbogin Sang Prabu. Tusing ada manah sangsaya I Mangku Tunden ngelanturang mamargi kapurian ngaturang saung kerise ento, pinaka cihna kerisne suba ilang ritatkala mamarga $k a$ purian”.

Terjemahan:

"Akhirnya demi sembah bhakti beliau kepada Sang Raja, walaupun ada halanagn tetap putuskan untuk tetap menghaturkan sarungnya walaupun kerisnya sudah tidak ada. Kalau I Mangku Tunden tidak menghaturkan keris itu kepada Sang Raja, Mangku Tunden dianggap berbohong oleh Sang Raja. Dengan rasa penuh kejujuran Mangku Tunden menghaturkan sarungnya saja sebagai bukti bahwa keris itu benar-benar hilang".

Pada tahap climax atau klimaks juga diceritakan Mangku Tunden pun lari dari Kerjaan Mengwi karena Sang Prabu memerintahkan prajuritnya untuk membunuh Mangku Tunden. Seperti dalam kutipan berikut. 
"Kacrita reko ring Puri Singhasan Keraton para pepatih sampun siaga, punika taler Para Tanda Mantri sayaga ngantosang sapatekan I Mangku Tunden, lantas teka I Mangku Tunden tumuli ngaturang miwah nyritayang kapiambeng ipune ring margi. Disubane kapireng critan I Mangku Tunden olih Sang Prabu maka miwah Para Patih, lantas ada orta-orta ne nyaurin critan ilangne kerise ento, sangkaning mula saja ilang ring margi apa ya I Mangku Tunden ne nyemak. Sangkaning orta-orta ne ento lantas Sang Prabu matimangtimang manah lantas ngandika olih I Mangku Tunden mogbogin Sang Prabu tuah I Mangku Tunden ne nyemak kerise ento. Lantas Sang Prabu mawacana winaya ring para Maha Patih ring Puri Mengwi nguber tumuli ngematiang I Mangku Tunden".

Terjemahan:

"Diceritakan Keadaan Puri Singhasan Keraton dan disertai dengan para Patih. Tanda Mantri sudah siap menunggu kedatangan Mangku Tunden. Kemudian tiba saatnya Mangku Tunden melaporkan dengan jujur perjalanannya dari awal sampai akhir. Setelah laporannya ditanggapi oleh raja dengan para patih, maka timbullah bermacam-macam tafsiran dan ada yang menanggapi apakah keris itu betul-betul hilang atau Mangku Tunden sendiri yang mengambilnya. Dengan bermacammacam tafsiran itu, raja mengambil kesimpulan dengan tegas menuduh Mangku Tunden kurang jujur. Dialah yang dianggap mengambil keris itu. Maka Sang Raja dengan tegas memerintahkan seluruh Maha Patih di Kerajaan Mengwi untuk membunuh Mangku Tunden. Mangku Tunden sendiri merasa dirinya dicurigai, akhirnya Mangku Tunden melarikan diri dari Kerajaan Mengwi".

Pada tahap denoument atau tahap penyelesaian diceritakan permaisuri dari Raja Bali akan melahirkan, namun bayinya tidak kunjung lahir. Akhirnya Sang Raja mendapatkan sabdha suci dari Ida Bhatara di Gunung Tohlangkir. Raja Bali memerintahkan para pandita Siwa maupun Budha untuk mencari Tirta Selaka tersebut. Akhirnya pada hari baik Budha Wage Ukir Tirta Selaka itu ditemukan di dalam sebuah goa di Desa Bantiran tempat Mangku Tunden bersembunyi. Tirta Selaka itupun diambil dan di bawa ke Kerajaan Kelungkung. Disiratkanlah Tirta Selaka tersebut ke permaisuri. Akhirnya bayi kembar buncing lahir dan diberikan Sri Masula-Sri Masuli. kutipan berikut.

"Rabi kantun mobot tan sue jagi embas putran ida. Ring dina okan idane lakar mapag embas sakewala rarene punika makelo tusing nyak embas.. Lantas Sang Prabu polih pawisik suci saking Tohlangkir. Tohlangkir ento adan Gunung Agunge ipidan, sane mangkin tongos Pura Besakih. "Panditane suba kautus kacrita pamarga panditane ento sida nети antar ring rahina Budha Wage Ukir tuah utusan panditane ento teka ring gua tongos nangun tapa maka miwah tongos I Mangku Tunden mengkeb. Suba ditengah guane lantas panditane ento nyemak Tirta Selakane ento aji pane, lantas abane nyantos ka Puri Klungkung, neked panditane ring Pamedalan Agug siratinne Tirtane ento papojolan embas rarene ento, tumuli rarene ento embas saha kembar buncing ne kawastanin Sri Masula-Sri Masuli”. 
Terjemahan:

"Permaisuri dari Raja sedang hamil menjelang akan melahirkan. Pada suatu hari, tibalah saatnya permaisuri akan melahirkan tetapi anak beliau tidak mau lahir atau keluarAkhirnya Sang Raja mendapatkan sabdha suci dari Ida Bhatara yang berada di Gunung Toh Langkir. Gunung Tohlangkir merupakan sebutan gunung agung jaman dahulu tempat dimana Pura Besakih berada. Isi sabdha itu adalah kalau Sang Raja menghendaki agar bayinya cepat lahir, Sang Raja harus mendapatkan Tirta Selaka .Pendeta itu berhasil dengan baik pada hari Budha Cemeng Ukir utusannya dari Klungkung sampai pada siang harinya di sebuah goa tempat pertapaan yaitu tempatnya Mangku Tunden bersembunyi. Kemudian masuklah mereka berdua ke dalam goa. Sesampai di dalam goa, pendeta pun mengambil air tersebut dengan sebuah mangkok. Kemudian dituntun ke Kerajaan Klungkung. Setelah Tirta Selaka itu dituntun sampai di Pemedalan Agung belum dipercikkan kehadapan permaisuri, saat itu juga bayi itu langsung lahir. Tetapi kelahiran dari bayi tersebut buncing (laki-laki dan perempuan) yang diberi nama Sri Masula-Sri Masuli".

\section{- Tokoh}

Tokoh adalah individu rekaan yang mengalami peristiwa atau berlakuan di dalam berbagai peristiwa cerita. Tokoh umumnya berwujud manusia, tetapi dapat juga berwujud binatang atau benda yang diinsankan (Sudjiman, 1988: 16). Tokoh utama dari teks mitos Tirta Selaka adalah Mangku Tunden. Sebagaimana dapat diijelaskan sebelumnya, Mangku Tunden merupakan tokoh utama karena dalam teks ini Mangku Tunden sering muncul dan berperan penting dari awal teks sampai akhir. Adapun tokoh sekunder dalam teks mitos Tirta Selaka di Pura Kereban Langit Desa Sading adalah Ida Bhatara Siwa Lingsir, Sang Prabu, Raja Bali, Pandita Siwa-Budha, dan para pemedek. Tokoh sekunder membantu dan juga menonjolkan pelaku utama yaitu Mangku Tunden dalam keseluruhan cerita, sehingga cerita menjadi menarik.

\section{- Tema}

Menurut Brooks (dalam Tarigan, 1984: 125) Tema adalah pandangan hidup tertentu atau perasaan tertentu mengenai kehidupan atau rangkaian nilai-nilai tertentu yang membentuk atau membangun dasar atau gagasan utama dari suatu karya sastra. Tema dalam teks Mitos Tirta Selaka di Pura Kereban Langit adalah tentang religius magis, karena kekuatan Tirta Selaka yang berada di luar akal manusia seperti memperoleh keturunan dan penyembuhan penyakit niskala dengan cara prosesi-prosesi keagamaan seperti penyucian dan naur sesangi. Dapat dilihat pada kutipan berikut.

"Lantas abane nyantos ka Puri Klungkung, neked panditane ring Pamedalan Agung siratine Tirtane ento papojolan embas rarene ento, tumuli rarene ento embas saha kembar buncing ne kawastanin Sri Masula-Sri Masuli”.

"Anake ne suba makurenan sane konden ngelah pianak, tangkil nunas ica mangdane sida ledang Ida Bhatra Siwa Lingsir memicayang pianak preti Santana lan pemedek sane lianan tangkil ke Pura Kereban Langit puniki nunas kesembuhan yening keni penyakit"

Terjemahan:

"Setelah Tirta Selaka itu dituntun sampai di Pemedalan Agung belum dipercikkan kehadapan permaisuri, saat itu juga bayi itu langsung lahir. 
Tetapi kelahiran dari bayi tersebut buncing (laki-laki dan perempuan) yang diberi nama Sri Masula-Sri Masuli”.

"Para pasutri yang belum memiliki keturunan, datang ke sana memohon kehadapan Ida Bhatara Siwa Lingsir agar dapat diberikan penerus keturunan/generasi dan pemedek yang lainnya tangkil memohon kesembuhan kalau terkena penyakit.

\section{- Latar}

Latar atau setting yang disebut juga sebagai landas tumpu, menyaran pada pengertian tempat, hubungan waktu, dan lingkungan sosial tempat terjadinya peristiwa-peristiwa yang diceritakan (Abrams, 1981: 175). Latar tempat dalam teks mitos Tirta Selaka di Pura Kereban Langit ada enam yaitu Puri Singhasan Keraton, Kerajaan Mengwi, Kerajaan di Klungkung, dalam goa, Sungai Lang, dan Pura Kereban Langit. Latar waktu dalam teks mitos Tirta Selaka di Pura Kereban Langit Desa Sading yaitu Budha Wage Ukir dan dulu. Teks mitos Tirta Selaka di Pura Kereban Langit menunjukkaan beberapa latar sosial. Salah satunya adalah yang berkaitan dengan tradisi dan keyakinan di masyarakat. Pasangan suami istri yang belum dikaruniai keturunan datang ke Pura Kereban Langit untuk memohon keturunan kehadapan Ida Bhatara Siwa Lingsir. Pemedek yang lain datang untuk memohon kesembuhan dengan cara masesangi. Doa para pemedek yang tangkil banyak yang terkabulkan, mereka mengucapkan rasa terimaksih dengan cara naur sesangi berupa dana punia, wastra, dan banten pejati. Seperti dalam kutipan berikut.

"liu anake ne suba makurenan sane konden ngelah pianak, tangkil nunas ica mangdane sida ledang Ida Bhatra Siwa Lingsir memicayang pianak preti Santana lan pemedek sane lianan tangkil ke Pura Kereban
Langit puniki nunas kesembuhan yening keni penyakit. Yening pemedek sane tangkil mriki akeh, krana doa pemedek nika akeh terkabul ulian ketulusan pamedek sane tangkil ke pura niki. Pemedek biasane ngaturang dana punia (mayah sesangi), wastra, miwah banten pejati”

Terjemahan:

"Banyak pasangan suami istri yang belum memiliki keturunan, datang ke sana memohon kehadapan Ida Bhatara Siwa Lingsir agar dapat diberikan penerus keturunan/generasi dan pemedek yang lainnya tangkil memohon kesembuhan kalau terkena penyakit. Kebanyakan doa mereka terkabulkan karena doa mereka yang tulus. Pemedek biasanya menghaturkan dana punia berupa uang (naur sesangi), wastra, dan banten pejati”.

- Amanat

Amanat merupakan pesan moral yang terkandung dalam sebuah karya sastra yang ingin disampaikan oleh pengarang kepada para pembaca atau penikmat karya sastra berupa nilai-nilai leluhur yang dapat dijadikan contoh atau teladan. Amanat yang diungkapkan pada teks mitos Tirta Selaka sebagai berikut:

1. Membiasakan hidup sabar dalam menghadapi cobaan dari Tuhan.

2. Rasa syukur atas anugerah yang diperoleh dari Tuhan

\section{Fungsi Teks Mitos Tirta Selaka di Pura Kereban Langit Desa Sading Kecamatan Mengwi}

Luxemburg (1984: 94) mengatakan fungsi adalah keseluruhan sifat-sifat yang bersama-sama menuju tujuan yang sama serta dampaknya. Sastra tidak hanya mencerminkan kenyataan, namun juga turut membangun masyarakat dan hendaknya berperan sebagai guru. Teks mitos Tirta 
Selaka di Pura Kereban Langit akan dianalisis menggunakan fungsi religius, fungsi pendidikan, fungsi magis, dan sebagai alat pengesahan pranata dan lembaga kebudayaan.

\section{- Fungsi Religius}

Tri dasar kerangka agama Hindu yang meliputi:tattwa/filsafat, susila/etika, dan upacara, ketiganya merupakan kesatuan yang harus dilaksanakan oleh umat Hindu. Tri kerangka agama Hindu ini merefleksikan dan mendasari kehidupan maupun interaksi social masyarakat untuk mendekatkan diri kepada Tuhan. Ajaran keagamaan dalam teks mitos Tirta Selaka akan dijelaskan mengenai unsur tattwa/filsafat, susila/etika, dan upacara. Tattwa/ Filsafat, kepercayaan dengan adanya Tuhan juga sangat terlihat dari masyarakat Desa Sading maupun luar Sading datang ke Pura Kereban Langit untuk memohon keturunan dan kesembuhan dari segala penyakit niskala kehadapan Ida Bhatara Siwa Lingsir (Ratu Gede). Susila/etika, cerminan fungsi susila yang tertuang dalam keyakinan masyarakat terhadap Pura Kereban Langit terdapat kepercayaan-kepercayaan masyarakat tentang mitos Tirta Selaka dalam segala tindakannya baik kegiatan keagamaan maupun lainnya didahului dengan memohon Ida Bhatara Siwa Lingsir agar keinginan pemohon terkabulkan. Hal ini membuktikan tindakan susila masyarakat yang senantiasa melestarikan kepercayaan terhadapa keberedaan Tirtha Selaka masih eksis sampai saat ini dan menunjukkan tindakan susila masyarakat yang selalu ingat terhadap Ida Bhatara Siwa Lingsir yang menggambarkan nilai Ketuhanan yang masih lestari di kalangan masyarakat Desa Sading. Upacara, pada teks mitos Tirta Selaka terdapat fungsi penyucian dan naur sesangi.

\section{- Fungsi magis}

Fungsi magis yang ada pada Tirta Selaka yaitu Jro Mangku Wayan Sweden menjelaskan bahwa Tirta Selaka ini tidak mudah didapatkan, karena yang hanya mendapatkan pawisik saja yang bisa mendapatkan Tirta Selaka ini. Pemangku Pura Kereban Langit tidak pernah membawa air dari rumahnya untuk dijadikan Tirta, jadi di pura ini hanya mengandalkan air pancoran yang terdapat di dalam goa Pura Kereban Langit. Titrha Selaka ini memang sangat bermanfaat, banyak penyakit yang pernah disembuhkan setelah meminum air suci ini. Pemangku mengatakan ada seseorang anak kecil sakit dan tidak kunjung sembuh. Akhirnya anak kecil itu dan keluarganya melukat di Pancoran Sapta Rsi yang terdapat di Pura Kereban Langit.

\section{- Sebagai Alat Pengesahan Pranata dan Lembaga Kebudayaan}

Teks mitos Tirta Selaka di Pura Kereban Langit terdapat lembaga kebudayaan yang samapai saat ini masih dilaksanakan menurut kepercayaan yaitu pemohon atau pemedek yang datang ke Pura Kereban Langit datang untuk memohon keturunan dan kesembuhan dari segala penyakit niskala dengan cara masesangi, setelah doa mereka terkabulkan bisa mempunyai keturunan dan memperoleh kesembuhan, pemohon membayar kaul atau naur sesangi. Membayar kaul atau naur sesangi merupakan sah secara kebudayaan.

\section{- Sebagai alat Pendidikan}

Fungsi pendidikan teks mitos Tirta Selaka di Pura Kereban Langit yaitu memahami dan menjalankan tradisi turun temurun yang telah dilaksanakan sejak dahulu, salah satunya tradisi yang dilaksanakan oleh masyarakat Desa Sading maupun masyarakat umum yaitu penyucian di Pura Kereban Langit.

\section{Simpulan}

Teks mitos Tirta Selaka di Pura Kereban Langit, Sading memiliki plot lurus atau alur maju terlihat dari rangkaian cerita dari keterkaitan objek sasaran cerita dari 
tahap awal hingga akhir. Tokoh utama dari teks mitos Tirta Selaka adalah Mangku Tunden. Tokoh sekunder dalam teks mitos Tirta Selaka di Pura Kereban Langit Desa Sading adalah Ida Bhatara Siwa Lingsir, Sang Prabu, Raja Bali, Pandita Siwa-Budha, dan para pemedek. Tokoh sekunder membantu dan juga menonjolkan pelaku utama yaitu Mangku Tunden dalam keseluruhan cerita. Tema dalam teks Mitos Tirta Selaka di Pura Kereban Langit adalah tentang religius magis. Dalam teks mitos ini terdapat latar yaitu latar tempat, latar waktu, dan latar sosial. Fungsi teks mitos Tirta Selaka di Pura Kereban Langit yaitu fungsi religius, fungsi pendidikan, fungsi magis, dan sebagai alat pengesahan pranata dan lembaga kebudayaan.

\section{Daftar Pustaka}

Danandjaja, James. 1984. Folklor Indonesia (Ilmu Gosip, Dongeng, dan lainlain). Jakarta: Grafitipers.

Kridalaksana, Harimurti, 2008. Kelas Kata dalam Bahasa Indonesia. Jakarta: PT Gramedia Pustaka Utama.

Luxemburg. Jan van dkk, 1984. Pengantar Ilmu Sastra (Terjemahan oleh Dick Hartoko dari Judul asli Inleiding in de Literaturewetencap). Jakarta: PT Gramedia.

Nurgiyantoro, Burhan. 1994: Teori Pengkajian Fiksi. Yogyakarta: Gadjah Mada University Press.

Ratna. I Nyoman Kutha. 2010. Metodelogi Penelitian: Kajian Budaya dan Ilmu Sosial Humaniora Pada Umumnya. Yogyakarta: Pustaka Pelajar.

Tarigan, Hendry Guntur. 1984. PrinsipPrinsip Dasar Sastra. Bandung: Angkasa.
Teeuw, A. 1984. Sastra dan Ilmu Sastra: Pengantar Teori Sastra. Jakarta: Pustaka Jaya.

Pradopo, Rachmat Djoko. 2007. Pengkajian Puisi, Analisis Sastra dan Analisis Struktural. Yogyakarta: Gadjah Mada University Press. 